\title{
NONLINEAR AND BUCKLING BEHAVIOR OF CURVED PANELS SUBJECTED TO COMBINED LOADS
}

AIAA-2001-1398

\author{
Mark W. Hilburger, ${ }^{*}$ Michael P. Nemeth, ${ }^{\dagger}$ and James H. Starnes, Jr. ${ }^{\ddagger}$ \\ NASA Langley Research Center \\ Hampton, Virginia 23681-001
}

\begin{abstract}
The results of an analytical study of the nonlinear and buckling response characteristics of curved panels subjected to combined loads are presented. Aluminum and laminated composite panels are considered in the study and a flat and shallow curved panel configurations are considered as well. The panels are subjected to combined axial compression and transverse tension or compression loads or combined axial compression and inplane shear loads. Results illustrating the effects of various combined load states on the buckling response of the panels are presented. In addition, results illustrating the effects of laminate orthotropy and anisotropy and panel curvature on the panel response are presented. The results indicate that panel curvature can have a significant effect on the nonlinear and buckling behavior of the panels subjected to combined loads. Results are included that show that geometrically perfect panels do not exhibit bifurcation points for some combined loads. Results are also presented that show the effects of laminate orthotropy and anisotropy on the interaction of combined loads.
\end{abstract}

\section{Introduction}

To achieve high performance in the next generation of aerospace structures, it will be necessary to develop reliable, high-fidelity design criteria for the buckling behavior of shell structures subjected to combined mechanical and thermal loads. For the past thirty years, buckling loads for shell structures have been obtained for design purposes, to a large extent, by conducting linear bifurcation analyses on idealized, geometrically perfect shell structures and by using empirical "knockdown" factors that account for the effects of initial geometric imperfections. ${ }^{1}$ In many cases, bifurcation-buckling interaction curves for shells subjected to combined loads have been approximated by a linear relationship between the bifurcation-buckling

\footnotetext{
*Aerospace Engineer, Mechanics and Durability Branch. Member, AIAA.

${ }^{\dagger}$ Senior Research Engineer, Mechanics and Durability Branch. Associate Fellow, AIAA.

${ }^{\ddagger}$ Senior Engineer, Structures and Materials Competency. Fellow, AIAA
}

Copyright 2001 by the American Institute of Aeronautics and Astronautics, Inc. No copyright is asserted in the United Stales under Title 17, U. S Code. The U.S. Government has a royalty-free license to exercise all rights under the copyright claimed herein for Governmental Purposes. AlI other rights are reserved by the copyright owner loads for each component of the combined loads. This type of approximation neglects the nonlinear interaction of the combined loads and results in an overly conservative prediction of the bifurcation-buckling load.

Often, empirical knockdown factors for shells with complex geometry and subjected to combined loads are unavailable, and analysis-based predictions of the sensitivity of the panel response to initial geometric imperfections and other complicating effects must be used. Ideally, highly accurate predictions of the response can be obtained when the initial geometric imperfections, material properties, thickness distribution, boundary conditions, and other features are known to a high level of accuracy. ${ }^{2}$ When these quantities are not well known, analysis-based lower-bound estimates that represent the effects of initial geometric imperfections in nonlinear analyses must be used. A common example of this approach is to use a bifurcation-mode imperfection shape to represent the initial geometric imperfections. This lower-bound, nonlinear-analysisbased approach has been applied to the Space Shuttle superlightweight external liquid-oxygen tank. ${ }^{3-7}$ This approach is inherently ultra-conservative and leads to an overweight structural design, but is often the only meaningful approach available to designers and analysts.

To complicate matters, recently it has been shown that geometrically perfect, shallow cylindrical panels that are subjected to combined axial compression along the generator and transverse tension or compression do not exhibit bifurcation points. ${ }^{8}$ This result was obtained by using an approximate special-purpose, singlemode nonlinear analysis and indicates a major shortcoming of the traditional shell stability design approach that is based on linear-bifurcation buckling analyses or results. The main objective of the present paper is to examine the nonlinear behavior of curved panels subjected to combined loads with a high-fidelity, nonlinear-analysis tool. This objective is achieved in the present paper by first describing the high-fidelity analysis tool, and then by presenting results for cylindrical panels made of aluminum and laminated-composite materials. In particular, the results address the behavior of simply supported cylindrical panels that are subject- 
ed to combinations of axial compression, transverse tension or compression, and shear loads. Results for flat plates and curved panels are included.

\section{Finite-Element Model and Analysis}

The panels considered in this study were analyzed with the STAGS finite-element code. ${ }^{9}$ The geometry and loading conditions and a typical finite-element model of a curved panel are shown in Fig. 1. Points on the panel mid-surface are located by an $x-y-z$ coordinate frame whose origin is at the lower left corner of the panel. The panel length, width, and radius are defined as $L$, $W$ and $R$ respectively. The panel length and width are $L$ $=W=14.0$ in., for all panels. Flat plates $(R=\infty)$ and a shallow curved panel with a radius of $R=60$ in. are considered in the present study. Simply supported boundary conditions are applied to the edges of the panels. The panels are loaded by uniform applied traction loads. Aluminum and laminated composite panels are considered in the investigation. The aluminum panels have a nominal thickness of $t=0.12 \mathrm{in}$. The nominal material properties are as follows: Young's modulus $E=10.0$ Msi, and Poisson's ratio $v=0.33$. The composite panels are 24-ply laminates. The lamina plies have a nominal thickness equal to 0.005 in., which corresponds to a nominal panel thickness of $t=0.12 \mathrm{in}$. The nominal unidirectional properties of a typical 0.005 -in-thick lamina ply are as follows: longitudinal modulus $E_{1}=19.5 \mathrm{Msi}$, transverse modulus $E_{2}=1.45 \mathrm{Msi}$, in-plane shear modulus $G_{12}=0.813 \mathrm{Msi}$, and major Poisson's ratio $\mathrm{v}_{12}=$ 0.30 . Three laminate stacking sequences are considered in the present study and include a quasi-isotropic $[ \pm 45 / 0 /$ $90]_{3 \mathrm{~s}}$ laminate, an axially stiff $\left[ \pm 45 / 0_{2}\right]_{3 \mathrm{~s}}$ laminate, and a transversely stiff $\left[ \pm 45 / 90_{2}\right]_{3 s}$ laminate. The finite-element models consist of four-node STAGS 410 quadrilateral shell elements. The STAGS 410 element is a flat facet-type element that is based on the Kirchoff-Love shell theory and the nonlinear Lagrangian-strain tensor. The element nodes include three rotational degrees of freedom and three translational degrees of freedom. Large rotations are accounted for by the use of a co-rotational algorithm.

The STAGS code uses both the modified and full Newton methods for its nonlinear solution algorithms. The equivalence transformation (ET) bifurcation processor is used to continue beyond bifurcation points into the postbuckling range of the solution. The ET processor allows the user to select a solution branch in the direction of growth of a bifurcation mode that has been computed for the nonlinear stress state in the neighborhood of the bifurcation point. This bifurcation mode is held constant with a magnitude specified by the user, and the load factor in the solution is adjusted until the solution residual vanishes.

The prebuckling responses were determined using the geometrically nonlinear quasi-static analysis capability in STAGS. The ET processor was used to obtain solutions beyond the bifurcation point and to branch onto the postbuckling equilibrium path of the panels. Once the initial postbuckling path was established, the analysis was continued into the postbuckling range by using the quasi-static analysis capability in STAGS. Linear bifurcation analysis were also conducted using the STAGS code. A typical finite-element model contained approximately 10,000 degrees of freedom.

\section{Results and Discussion}

The buckling and nonlinear response of panels subjected to combined loads are presented. The results are presented to illustrate the nonlinear behavior of curved panels subjected to combined loads. First, results illustrating the response of flat aluminum plates subjected to combined loads are presented. Then results illustrating the effects of panel curvature on the nonlinear response are presented. Finally, results illustrating the effects of laminate orthotropy and anisotropy on the buckling loads of the panels subjected to combined loads are presented.

\section{Aluminum Flat Plates}

Nonlinear response curves for geometrically perfect, flat plates subjected to axial compression and transverse tension or compression loads are presented in Fig. 2. In particular, five curves are presented in Fig. 2a that show the nondimensional load as a function of the average end shortening (referred to herein as load-end-shortening curves for convenience) that correspond to the load ratio $\mathrm{N}_{\mathrm{y}} / \mathrm{N}_{\mathrm{x}}=-1,-0.5,0,0.5$, and 1 . Similarly, five corresponding curves are presented in Fig. $2 b$ that show the nondimensional load as a function of the out-of-plane or normal displacement at the center of the plate. These curves are referred to herein as load-normal-displacement curves for convenience. The ordinate is nondimensionalized by the value of the unidirectional compression stress resultant (i.e. $N_{y} / N_{x}=0$ ) in the plate at the bifurcation point; that is, $\left(\mathrm{N}_{\mathrm{x}}\right)^{0}{ }_{\text {bif }}=325.5 \mathrm{lbf} / \mathrm{in}$. The end-shortening and panel normal displacements are nondimensionalized by the panel length $L=14$ in. and thickness $t=0.12$ in., respectively. Negative and positive values of the load ratio correspond to transverse tension and compression loads, respectively. The filled circle on each curve represents the bifurcation point.

The results in Fig. 2a indicate that the bifurcation point of the plate considered increases with increasing transverse tension load and decreases with increasing transverse compression load, as expected. The values of the nondimensional buckling loads range from 0.5 to 2.08. In addition, the results show a decrease in preb- 
uckling axial stiffness with increasing transverse tension load and the opposite trend is shown for an increase in transverse compression load. The results in Fig. $2 \mathrm{~b}$ indicate that the magnitude of the postbuckling normal displacement at the center of the plate increases with an increase in the transverse compression load and decreases with and increase in the transverse tension load. The displacement response is characterized by a monotonically increasing center displacement with increasing applied load after buckling. In addition, the shapes of the curves indicate that the stiffness of the panel increases with decreasing $\mathrm{N}_{\mathrm{y}}$ (tension). Moreover, the results in Figs. $2 a$ and $2 b$ indicate that the buckling loads obtained from a nonlinear analysis (referred to herein as nonlinear-buckling loads) are identical to the linear bifurcation buckling loads for all load ratios, and these results are summarized in Table 1.

Nonlinear response curves for geometrically perfect flat plates subjected to axial compression and inplane shear loads are presented in Fig. 3. In particular, three load-end-shortening response curves and three load-normal-displacements response curves are shown for values of the load ratio $N_{x y} / N_{x}= \pm 1, \pm 0.5$, and 0 in Figs. $3 a$ and $3 b$, respectively. The ordinate is nondimensionalized by the value of the uniaxial compression stress resultant (i.e. $N_{x y} / N_{x}=0$ ) in the plate at the bifurcation point; that is, $\left(\mathrm{N}_{\mathrm{x}}\right)^{0}{ }_{\text {bif. }}$. The end-shortening and panel normal displacements are nondimensionalized by the panel length $L$ and thickness $t$, respectively. Positive and negative values of the load ratio correspond to positive and negative in-plane shear loads, respectively. The filled circle on each curve represents the bifurcation point.

The results in Fig. 3a indicate that the bifurcation point of the plate considered decreases with increasing in-plane shear load, as expected. The normalized buckling loads are $0.86,0.96$ and 1.0 for load ratios $\mathrm{N}_{x y} / \mathrm{N}_{\mathrm{x}}$ $= \pm 1, \pm 0.5$, and 0 , respectively. The decrease in buckling load is attributed to the diagonal compression generated by the shear load, however, the shear load has a smaller effect on the response than an applied transverse compression load $\mathrm{N}_{\mathrm{y}}$ because it produces a smaller-magnitude compression load than the transverse compression load. The results also show that the prebuckling axial stiffness is the same for all values of inplane shear loads. The results in Fig. 3b indicate that the magnitude of the normal displacement at the center of the plate decreases with an increase in the in-plane shear load. The displacement response is characterized by a monotonically increasing center displacement with increasing applied load after buckling occurs. However, unlike the results for the transverse compressionloaded plates, the postbuckling stiffness does not vary substantially with the amount of shear load applied to the panel. In addition, the results indicate that the nonlinear buckling loads for all load ratios agree well with the linear bifurcation buckling loads and are summarized in Table 2.

Typical bifurcation mode shapes for square aluminum flate plates subjected to combined axial compression and transverse tension or compression loads or axial compression and in-plane shear loads are shown in Fig. 4. The solid and dashed contour lines in the figure indicate positive and negative normal displacements, respectively and the density of the lines indicates the severity of the displacement gradient The results indicate that, for panels subjected to uniaxial and biaxial compression loads, that is, values of the load ratio $\mathrm{N}_{\mathrm{y}} / \mathrm{N}_{\mathrm{x}}=-1,-0.5$, and 0 , the mode shape is characterized by a single half-wave response, as shown in Fig. $4 a$. In contrast, the results indicate that the mode shape is characterized by a single half-wave across the width of the plate and two half-waves along the panel length, for values of the load ratio $N_{y} / N_{x}=1$, and 0.5 , as shown in Fig. 4b. A typical bifurcation mode shape for a panel subjected to combined axial compression and in-plane shear loads $\left(\mathrm{N}_{\mathrm{xy}} / \mathrm{N}_{\mathrm{x}}=1\right)$ is shown in Fig. $4 \mathrm{c}$, and is characterized by a skewed single half-wave mode shape which exhibits a central point of inversion symmetry (polar symmetry). The buckling displacements predicted from a nonlinear analysis of the aluminum flat plates are identical to the predicted bifurcation-buckling mode shapes, for all loading cases considered.

\section{Aluminum Curved Panels}

Nonlinear response curves are shown in Fig. 5 for the curved panels with $R / t=500(R=60 \mathrm{in}$.) subjected to combined axial compression and transverse tension or compression. In this figure, six load-end-shortening response curves and six load-normal-displacement response curves are shown for values of the load ratio $\mathrm{N}_{\mathrm{y}}$ $N_{x}=-1,-0.5,-0.1,0,0.5$ and 1 . The ordinate is nondimensionalized by the value of the uniaxial compression stress resultant $\mathrm{N}_{\mathrm{y}} / \mathrm{N}_{\mathrm{x}}=0$ (i.e. $\mathrm{N}_{\mathrm{y}} / \mathrm{N}_{\mathrm{x}}=0$ ) in the plate at the bifurcation point; that is, $\left(\mathrm{N}_{\mathrm{x}}\right)^{0}$ bif $=723.4 \mathrm{lb} / \mathrm{in}$. The end-shortening and panel normal displacements are nondimensionalized by the panel length $L=14$ in. and thickness $t=0.12$ in., respectively. Negative and positive values of the load ratio correspond to transverse tension and compression loads, respectively. The open circle and square symbols on each curve indicates the bifurcation point and limit point, respectively.

The results in Fig. $5 \mathrm{a}$ indicate that only the curved panel loaded by uniaxial compression, that is $\mathrm{N}_{\mathrm{y}} / \mathrm{N}_{\mathrm{x}}=$ 0 , exhibits a bifurcation point. The nonlinear-bucklingload value obtained from the nonlinear analysis $\left(\mathrm{N}_{\mathrm{x}}=\right.$ 
$720.3 \mathrm{lb} / \mathrm{in}$.) is within $1 \%$ of the load value obtained from the linear-bifurcation analysis. Moreover, the curved panel with $\mathrm{N}_{\mathrm{y}} / \mathrm{N}_{\mathrm{x}}=-0.1$ exhibits a limit point at a load level of $383.5 \mathrm{lb} / \mathrm{in}$. The limit point for this panel is significantly less than the corresponding bifurcationbuckling load equal to $727.2 \mathrm{lb}$./in. The remainder of the panels exhibit a benign, monotonically increasing nonlinear response. The normalized nonlinear normal displacement response curves for the panels are shown in Fig. $5 b$. The results indicate that the panel subjected to uniaxial compression $\left(\mathrm{N}_{\mathrm{y}} / \mathrm{N}_{\mathrm{x}}=0\right)$ does not exhibit any prebuckling normal deformations. After buckling, however, the panel exhibits significant inward radial deformations as indicated by the negative values of the normalized center displacement response. In contrast, the panels subjected to combined axial compression and transverse tension or compression do not exhibit a bifurcation type response, rather, they exhibit monotonically increasing load versus normal displacement responses from the onset of loading. The panels subjected to biaxial compression exhibit positive outward normal deformations, and the panel subjected to combined axial compression and transverse tension exhibit negative inward normal deformations that have the characteristics of initial geometric imperfections. The nonlinear, monotonically increasing load-endshortening behavior of the panels, shown in Fig 5a, is attributed to the normal deformation response exhibited by the panels. More specifically, as the panels deform during loading, the geometric stiffness of the panel changes which causes the effective axial stiffness of the panel to change in a gradual nonlinear manner as indicated by the nonlinear response shown in Fig. 5a. This gradual change in axial stiffness is in contrast to the rapid change in axial stiffness of a panel that exhibits a bifurcation-buckling type response. Overall, these highfidelity results verify the approximate results presented in Ref. 8 and indicate generally that linear-bifurcation analyses may be misleading for curved panels subjected to combined axial compression and transverse tension or compression loads. In addition, these results suggest that curved panels subjected to this type of combined loading condition may not have a high degree of imperfection sensitivity. A summary of the predicted bifurcation-buckling loads and the nonlinear-buckling loads for the curved aluminum panels are present in Table 1.

Nonlinear response curves for geometrically perfect curved panels subjected to axial compression and inplane shear loads are presented in Fig. 6. Three loadend-shortening curves and three load-normal-displacements curves are shown for values of the load ratio $\mathrm{N}_{\mathbf{x y}}{ }^{\prime}$ $N_{x}= \pm 1, \pm 0.5$, and 0 in Figs. $6 \mathrm{a}$ and $6 \mathrm{~b}$, respectively. The ordinate is nondimensionalized by the value of the uniaxial compression stress resultant (i.c. $\mathrm{N}_{\mathrm{x} \gamma} / \mathrm{N}_{\mathrm{x}}=0$ ) in the plate at the bifurcation point; that is, $\left(\mathrm{N}_{\mathrm{x}}\right)^{6}$ bif $=723.4$ $\mathrm{lbf}$./in. The end-shortening and panel normal displacements are nondimensionalized by the panel length $L$ and thickness $t$, respectively. Positive and negative values of the load ratio correspond to positive and negative inplane shear loads, respectively. The open circle on each curve represents the bifurcation point.

The results in Fig. 6a indicate that the bifurcation point of the compression-loaded panel considered decreases with increasing in-plane shear load, as expected. The normalized buckling loads are $0.79,0.93$ and 1.0 for values of the load ratio $N_{x y} / N_{x}= \pm 1, \pm 0.5$, and 0 , respectively. In particular, the curved panel with a load ratio value of $\mathrm{N}_{x y} / \mathrm{N}_{\mathrm{x}}= \pm 1$ exhibits a normalized buckling load of 0.79 as compared to the corresponding flat plate which exhibits a normalized buckling load equal to 0.86 . This result suggests that panel curvature can have a significant effect on the response of the panel to combined loads. The results also show that the prebuckling axial stiffness is the same for all values of in-plane shear loads. The bifurcation point is followed by an unstable buckling response. In addition, the results indicate that the curved panel subjected to combined axial compression and in-plane shear loads exhibit bifurcation-buckling type responses for all load ratios considered. In contrast, the corresponding panels subjected to combined axial compression and transverse tension or compression loads exhibit monotonically increasing, stable responses. The nonlinear normal displacement response curves for the panels are shown in Fig. 6b. The results indicate that during the prebuckling response the panels do not exhibit any normal deformations, however, the post buckling displacement response of the panels is characterized by large magnitude inward normal displacements of the central region of the panels.

A comparison of bifurcation mode shapes and buckling deformation patterns predicted from a nonlinear analysis for square aluminum curved panels subjected to combined axial compression and transverse tension or transverse compression loads or axial compression and in-plane shear loads are shown in Fig. 7. The solid and dashed contour lines in the figure indicate positive and negative normal displacements, respectively, and the density of the lines indicates the severity of the displacement gradient. The results indicate that the predicted bifurcation mode shape for a panel subjected to uniaxial compression exhibits a single halfwave response and is characterized by a deformation pattern ellipse-shaped contours, as shown in Fig. 7a. The results also indicate that the buckling deformation pattern predicted from a nonlinear analysis of the panel 
agrees well with the bifurcation mode shape. The results indicate that, for a panel subjected to biaxial compression with a load ratio $\mathrm{N}_{y} / \mathrm{N}_{x}=1$, the panel deformation response is characterized by a single halfwave response, as shown in Fig. $7 \mathrm{~b}$. However, these results indicate that there is a slight difference in the deformation pattern determined by a linear bifurcation analysis compared to the nonlinear deformation pattern. More specifically, the bifurcation buckling mode shape is characterized by a deformation pattern with ellipseshaped contours and is in contrast to a deformation pattern predicted with circular-shaped contours from a nonlinear analysis. The results indicate that, for a panel subjected to axial compression and transverse tension with a load ratio $\mathrm{N}_{\mathrm{y}} / \mathrm{N}_{\mathrm{x}}=-1$, the bifurcation buckling mode shape is characterized by two half-waves across the width of the plate and one half-wave along the panel length as shown in Fig. 7c. However, the predicted deformation pattern from a nonlinear analysis is characterized by a single half-wave response. A typical bifurcation mode shape for a panel subjected to combined axial compression and in-plane shear loads with a load ratio $N_{y} / N_{x}=1$ is shown in Fig. $7 d$, and is characterized by a skewed single-half wave mode shape which exhibits a central point of inversion symmetry. The corresponding predicted buckling displacements of the panel from a nonlinear analysis agree well with the predicted bifurcation buckling mode shape. The results in Fig. 7 indicate that the predicted bifurcation buckling mode shapes agree with buckling deformation patterns predicted from a nonlinear analysis when the nonlinear response exhibits a bifurcation response, e.g., panels subjected to uniaxial compression loads or combined axial compression and in-plane shear loads, and do not exhibit a prebuckling normal deformations. However, for curved panels subjected to combined loads that do not exhibit a bifurcation-buckling type response, the predicted bifurcation mode shapes tend to differ from the deformation patterns predicted from a nonlinear analysis and may be misleading.

\section{Effects of Laminate Orthotropy and Anisotropy}

Results for three laminates including a quasi-isotropic $[ \pm 45 / 0 / 90]_{3 \mathrm{~s}}$ laminate, an axially stiff $\left[ \pm 45 / 0_{2}\right]_{3 \mathrm{~s}}$ laminate, and a transversely stiff $\left[ \pm 45 / 90_{2}\right]_{3 \mathrm{~s}}$ laminate were obtained to illustrate the effects of laminate orthotropy and anisotropy on the nonlinear and buckling response of the panels. Similar results to those presented for the aluminum panels were obtained and indicate that, in general, the nonlinear and buckling response characteristics for the composite laminated panels are similar to those exhibited by the aluminum panels. Results illustrating the effects of orthotropy on the buckling loads of the flat plates and curved panels subjected to combined loads are presented in this section. Results for flat plates and curved panels subjected to combined axial compression and transverse tension or compression loads are presented in Figs. $8 \mathrm{a}$ and b, respectively. Bifurcation-buckling loads and buckling loads predicted from a nonlinear analysis are denoted by the square and triangle symbols, respectively. The bifurcation-buckling values of the load $\mathrm{N}_{\mathrm{x}}$ are denoted by $\left(\mathrm{N}_{\mathrm{x}}\right)_{\text {bif }}$ in the figure, and $\left(\mathrm{N}_{\mathrm{x}}\right)^{0}$ bif corresponds to the buckling load value for a given panel with $\mathrm{N}_{\mathrm{y}} / \mathrm{N}_{\mathrm{x}}=0$. Similarly, the buckling load predicted from a nonlinear analysis are denoted by $\left(\mathrm{N}_{\mathrm{x}}\right)_{\mathrm{cr}}$ in the figure and $\left(\mathrm{N}_{\mathrm{x}}\right)^{0}$ cr corresponds to the buckling value for a given panel with $N_{y} / N_{x}=0$.

The results in Fig. 8 show that panel curvature and laminate orthotropy can have a significant effect on buckling response of the panels subjected to combined axial compression and transverse tension loads (load ratio $\mathrm{N}_{\mathrm{y}} / \mathrm{N}_{\mathrm{x}}=-1$, and -0.5 ). More specifically, the results in Fig. 8a indicate that axially stiff composite flat plates have higher values of normalized buckling loads that range from 1.0 to 2.46 followed by the results for the aluminum and quasi-isotropic composite panels, which exhibit nearly identical nondimensional buckling loads, with normalized buckling load values that range from 1.0 to 2.06 for the loading conditions considered, and finally the results for the transversely stiff composite flat plates with normalized buckling load values that range from 1.0 to 1.52 . In contrast, the results indicate that the flat plates exhibit the same nondimensional buckling loads when subjected to uniaxial and biaxial compression loads (load ratio $N_{y} / N_{x}=0,0.5$, and 1). In addition, the results indicate that the nonlinear-bucking loads agree well with the predicted bifurcation-buckling loads for these flat plates and the values are generally with in $1 \%$. The results presented in Fig $8 \mathrm{~b}$ indicate that the curved panels with $R / t=500$ exhibit a similar trend; that is, the nondimensional buckling loads are generally higher for the axially stiff composite panels followed by the results for the aluminum and quasi-isotropic composite panels and finally the results for the transversely stiff composite panels. However, the degree of variation in the values of the normalized bifurcation-buckling loads is much less than that exhibited by the flat plates. These results suggests that a nonlinear coupling exists between the panel curvature and laminate orthotropy for the panels considered. In addition the results indicate that the curved pancls subjected to the combined axial compression and transverse tension or compression loads do not exhibit a bifurcation point, thus these bifurcation-buckling results may be misleading since bifurcation buckling may have no meaning in the context of curved panels subjected to 
these types of combined loads.

Results are presented for flat plates and curved panels subjected to combined axial compression and inplane shear loads in Figs. 9a and b, respectively. The results indicate that panel curvature and laminate orthotropy and anisotropy can have an effect on the nondimensional buckling load values for the loading conditions considered. More specifically, the results in Fig. 9a suggest that, for the flat plates, panel orthotropy has little effect on the nondimensional buckling load level as is evidenced by that fact that all the results for the composite flat plates are nearly identical for all values of the load ratio $N_{x y} / N_{x}$. However, the results also suggest that the response is affected by laminate anisotropy. More specifically, the results show that the buckling load value is dependent on the sign of the load ratio, that is the buckling load value is dependent on whether the in-plane shear load is positive or negative. For example, The composite plates with a load ratio $N_{x y} / N_{x}=-1$, corresponding to a negative in-plane shear load, exhibit a nondimensional buckling load of 0.835 , however, the composite plates with a load ratio $\mathrm{N}_{\mathrm{xy}}$ / $N_{x}=+1$, which corresponds to a positive in-plane shear load, exhibit a nondimensional buckling load of 0.875 . This result is in contrast to the results for the aluminum plate in which the buckling loads are independent of the sign of the load ratio. The results for the curved panels subjected to combined axial compression and in-plane shear loads are presented in Fig. 9b. The result indicate a similar trend to that exhibited by the corresponding flat plates. However, the results indicate that, in general, the curved panels exhibit lower normalized buckling loads when subjected to combined loads than do the corresponding flat plates. In addition, the results indicate that laminate anisotropy affects the buckling loads of the curved panels in a similar manner to that exhibited by the flat plates as evidenced by the dependence of the buckling load on the sign of the in-plane shear load. Moreover, the results indicate that laminate orthotropy of the panels considered also has a slight effect on the buckling response. More specifically, the results indicate that the transversely stiff panels have higher values of normalized buckling loads which range in value from 0.8 to 1.0 followed by the axially stiff, quasi-isotropic, and aluminum panels with values of normalized buckling loads that range from 0.77 to 1.0 .

\section{Concluding Remarks}

High-fidelity analysis tools and advanced computational capability now make it possible to develop reliable, high-fidelity design criteria for the buckling behavior of shell structures subjected to combined mechanical and thermal loads. As part of updating and developing such design criteria, in-depth examination of the nonlinear response of shells subjected to combined loads is needed. The present paper addressed this basic need by presenting results and discussion for flat plates and curved pancls subjected to a variety of combined loading conditions. In particular, results for loading conditions that involve combinations of axial compression, transverse tension or compression, and shear loads have been presented. Results that illustrate the effects of laminate orthotropy and anisotropy have also been presented. The results indicated that panel curvature can have a significant effect on the response of panels subjected to combined loads. In particular, curved panels subjected to combined axial compression and transverse tension or compression loads do not exhibit a bifurcation-buckling type response. As a result, a linear bifurcation analysis could misrepresent the physical behavior of the panel. The results also indicated that laminate orthotropy and anisotropy can have a substantial effect the buckling loads of the flat plates and curved panels subjected to combined loads. These results should be of interest to engineers designing practical shell structures.

\section{$\underline{\text { References }}$}

1. Nemeth, M. P. and Starnes, J. H., Jr., "The NASA Monographs on Shell Stability Design Recommendations - A Review and 'Suggested Improvements," NASA TP-1998-206290, January 1998.

2. Hilburger, M. W. and Starnes, J. H., Jr., "Effects of Imperfections on the Buckling Response of Compression-Loaded Composite Shells," AIAA Paper No. 20001387, April 2000.

3. Nemeth, M. P., Britt, V. O., Young, R. D., Collins, T. J., and Starnes, J. H., Jr., "Nonlinear Behavior of Space Shuttle Superlightweight Liquid-Oxygen Tank Under Prelaunch Loads," Journal of Spacecraft and Rockets, Vol. 36, No. 6, November-December, 1999, pp. 788-803.

4. Young, R. D. and Rankin, C. C., "Modeling and Nonlinear Structural Analysis of a Large-Scale Launch Vehicle," Journal of Spacecraft and Rockets, Vol. 36, No. 6, November-December, 1999, pp. 804-811.

5. Nemeth, M. P., Young, R. D., Collins, T. J., and Starnes, J. H., Jr.," Effects of Welding-Induced Imperfections on Behavior of Space Shuttle Superlightweight Tank," Journal of Spacecraft and Rockets, Vol. 36, No. 6, November-December, 1999, pp. 812-819.

6. Young, R. D., Nemeth, M. P., Collins, T. J., and Starnes, J. H., Jr., "Nonlinear Behavior of Space Shuttle Superlightweight Tank Under Booster Ascent Loads," Journal of Spacecraft and Rockets, Vol. 36, No. 6, November-December, 1999, pp. 820-827. 
7. Nemeth, M. P., Young, R. D., Collins, T. J., and Starnes, J. H., Jr., "Nonlinear Behavior of Space Shuttle Superlightweight Tank Under End-of-Flight Loads," Journal of Spacecraft and Rockets, Vol. 36, No. 6, November-December, 1999, pp. 828-835.

8. Librescu, L., Nemeth, M. P., Starnes, J. H., Jr., and Lin, W., "Nonlinear Response of Flat and Curved Panels Subjected to Thermomechanical Loads," Journal of Thermal Stresses, Vol. 23, No. 6, August, 2000, pp. 549-582.
9. Rankin, C. C., Brogan, F. A., Loden, W. A. and Cabiness, H. D., STAGS Users Manual, Lockheed Palo Alto Research Laboratory, Report LMMS P032594, 1999.

Table 1: Buckling loads for aluminum panels subjected to combined axial compression and transverse tension or compression loads.

\begin{tabular}{|c|c|c|c|c|}
\hline \multirow[b]{2}{*}{$\begin{array}{c}\text { Loading } \\
\text { Ratio, } \\
\mathbf{N}_{\mathbf{y}} / \mathbf{N}_{\mathbf{x}}\end{array}$} & \multicolumn{2}{|c|}{$\mathbf{R} / \mathbf{t}=\infty($ Flat plate $)$} & \multicolumn{2}{|c|}{$R / t=500$} \\
\hline & $\begin{array}{l}\text { Bifurcation- } \\
\text { buckling } \\
\text { Ioad }\left(\mathbf{N}_{\mathbf{x}}\right)_{\mathbf{b i f}}, \\
\text { lbffin. }\end{array}$ & $\begin{array}{c}\text { Nonlinear- } \\
\text { buckling } \\
\text { load }\left(\mathrm{N}_{\mathrm{x}}\right)_{\mathrm{cr}} \\
\text { lbf/in. }\end{array}$ & $\begin{array}{l}\text { Bifurcation- } \\
\text { buckling } \\
\text { load }\left(N_{x}\right)_{\text {bif }} \\
\text { lbf/in. }\end{array}$ & $\begin{array}{l}\text { Nonlinear- } \\
\text { buckling } \\
\text { load }\left(\mathrm{N}_{\mathrm{x}}\right)_{\mathrm{cr}} \\
\text { lbffin. }\end{array}$ \\
\hline-1.0 & 677.7 & 677.7 & 1215 & $-{ }^{a}$ \\
\hline-0.5 & 581.1 & 581.1 & 1051 & $-{ }^{a}$ \\
\hline-0.1 & - & - & 727.2 & $383.5^{\mathrm{b}}$ \\
\hline 0.0 & 325.6 & 325.6 & 723.4 & 720.3 \\
\hline 0.5 & 217.0 & 217.0 & 496.5 & $-{ }^{a}$ \\
\hline 1.0 & 162.8 & 162.8 & 376.3 & $\ldots^{\mathrm{a}}$ \\
\hline
\end{tabular}

a Monotonically increasing response which does not exhibit a bucking point

${ }^{b}$ Limit point

Table 2: Buckling loads for aluminum panels subjected to combined axial compression and in-plane shear loads.

\begin{tabular}{|c|c|c|c|c|}
\hline \multirow[b]{2}{*}{$\begin{array}{l}\text { Loading } \\
\text { Ratio, } \\
\mathbf{N}_{\mathbf{x y}} / \mathbf{N}_{\mathbf{x}}\end{array}$} & \multicolumn{2}{|c|}{$\mathbf{R} / \mathbf{t}=\infty$ (Flat plate $)$} & \multicolumn{2}{|c|}{$R / t=500$} \\
\hline & $\begin{array}{c}\text { Bifurcation- } \\
\text { buckling } \\
\text { load }\left(\mathbf{N}_{\mathbf{x}}\right)_{\text {bif }} \\
\text { lbf } / \text { in. }\end{array}$ & $\begin{array}{l}\text { Nonlinear- } \\
\text { buckling } \\
\text { load }\left(\mathbf{N}_{\mathbf{x}}\right)_{\mathrm{cr}} \\
\text { lbffin. }\end{array}$ & $\begin{array}{c}\text { Bifurcation- } \\
\text { buckling } \\
\text { load }\left(\mathbf{N}_{\mathbf{x}}\right)_{\text {bif }} \\
\text { lbf } / \text { in. }\end{array}$ & $\begin{array}{c}\text { Nonlinear- } \\
\text { buckling } \\
\text { load }\left(\mathbf{N}_{\mathbf{x}}\right)_{\mathrm{cr}} \\
\text { lbf/in. }\end{array}$ \\
\hline-1.0 & 281.1 & 281.1 & 570.9 & 568.5 \\
\hline-0.5 & 312.0 & 312.0 & 674.8 & 666.1 \\
\hline 0.0 & 325.6 & 325.6 & 723.4 & 720.3 \\
\hline 0.5 & 312.0 & 312.0 & 674.8 & 666.1 \\
\hline 1.0 & 281.1 & 281.1 & 570.9 & 568.5 \\
\hline
\end{tabular}



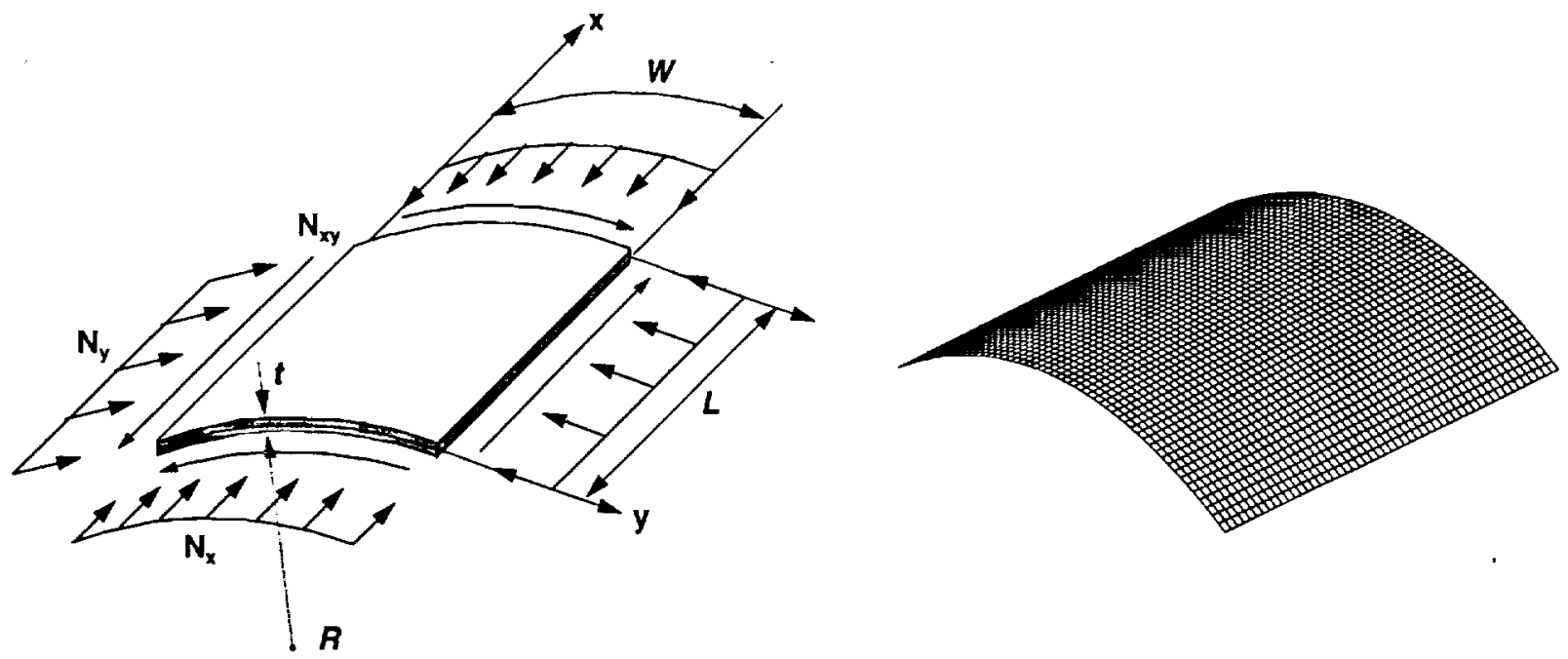

Fig. 1 Typical panel geometry and loading conditions and finite-element model.

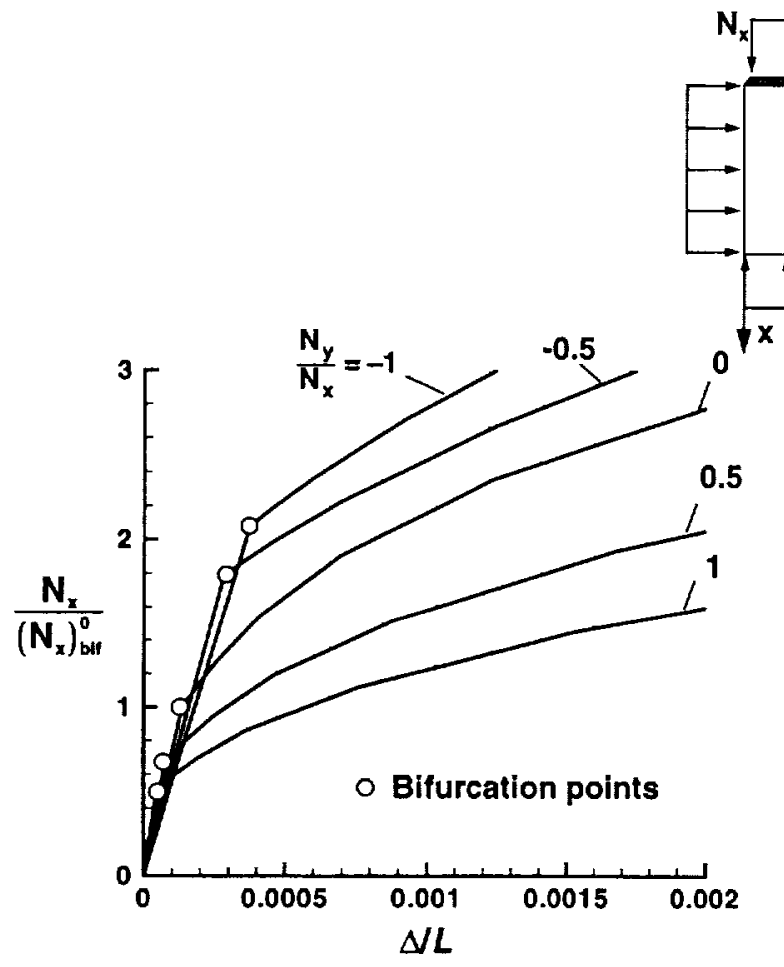

a) Load-end-shortening response

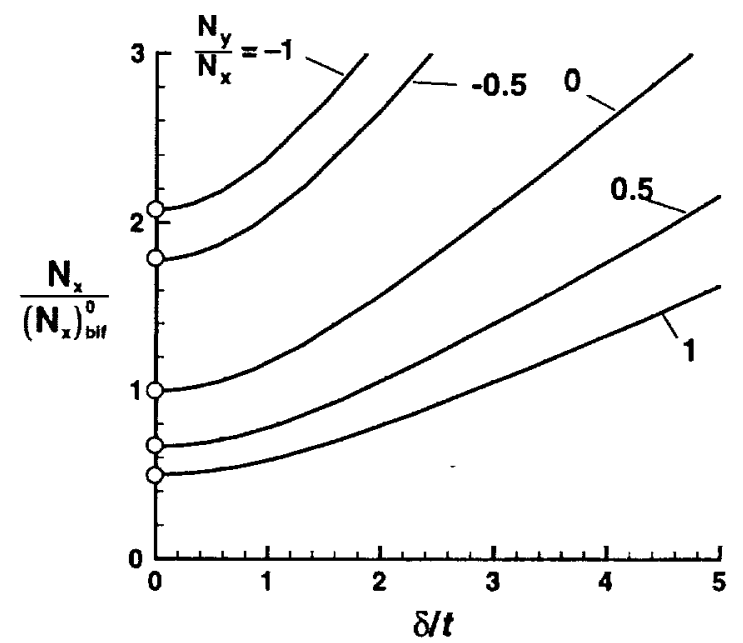

b) Load-normal-displacement response

Fig. 2 Nonlinear response of square aluminum flate plates subjected to combined axial compression and transverse tension or compression loads $\left(L=14.0 \mathrm{in}\right.$, $t=0.12 \mathrm{in}$, $\left(\mathrm{N}_{\mathrm{x}}\right)^{0}{ }_{\mathrm{bif}}=325.5 \mathrm{lb} / \mathrm{in}$.). 


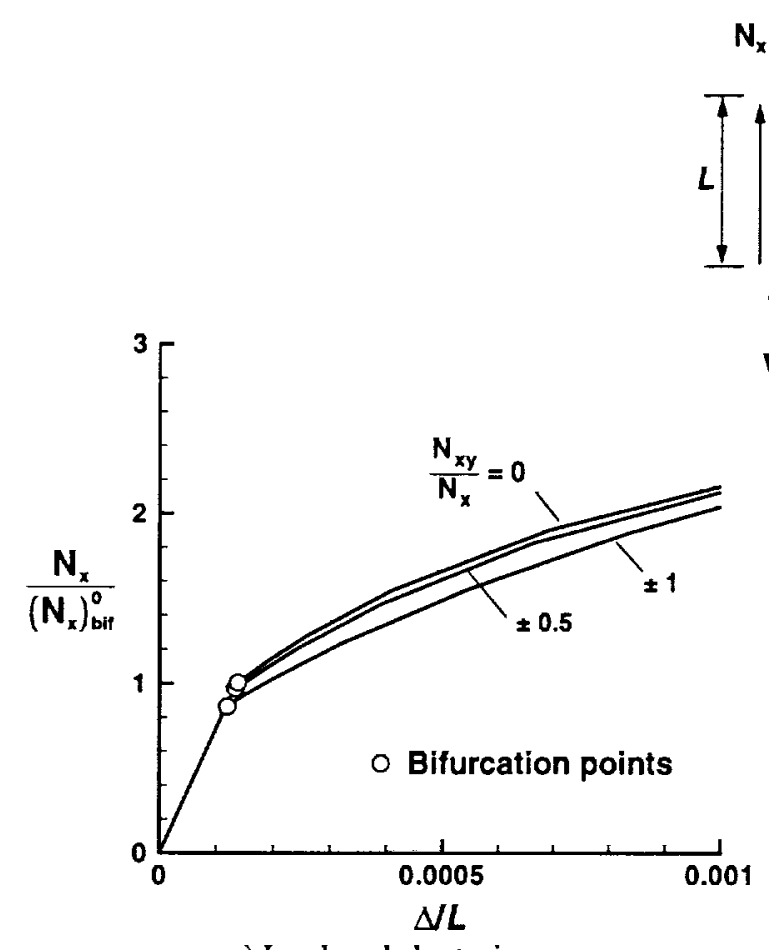

a) Load-end-shortening response
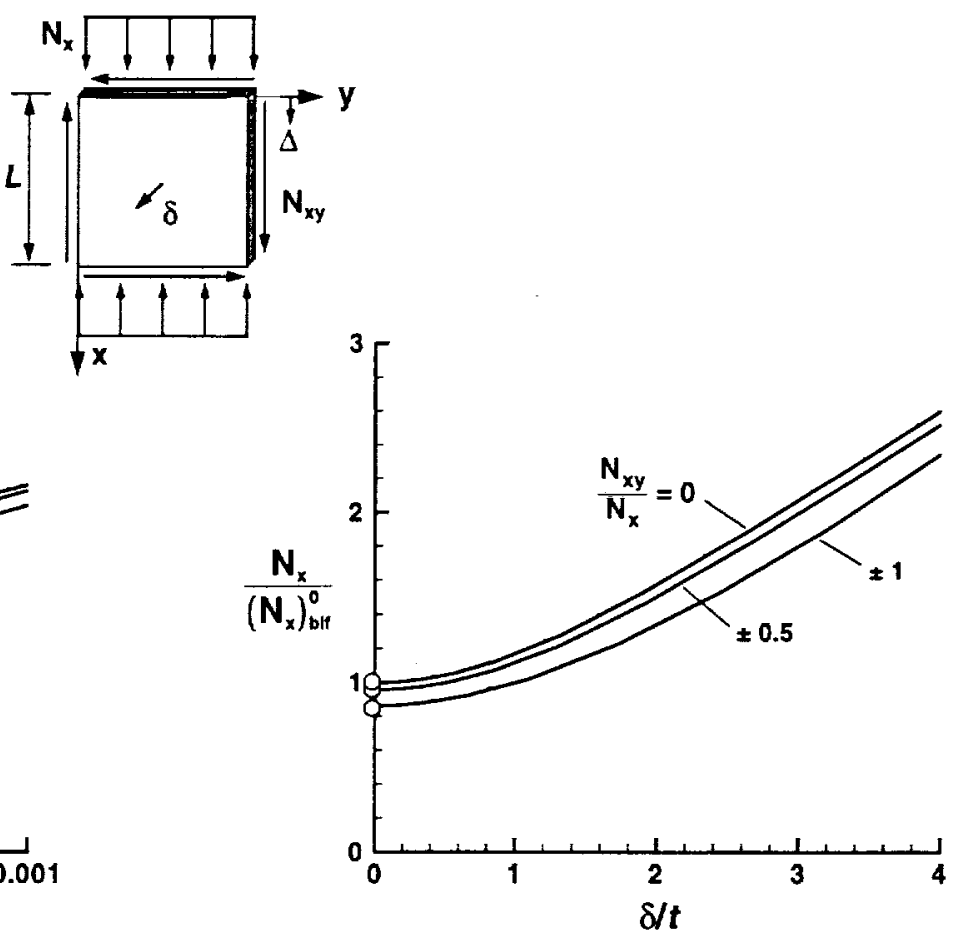

b) Load-normal-displacement response

Fig. 3 Nonlinear response of square aluminum flate plates subjected to combined axial compression and in-plane shear loads $\left(L=14.0 \mathrm{in}\right.$., $t=0.12 \mathrm{in}$., $\left(\mathrm{N}_{\mathrm{x}}\right)_{\mathrm{bif}}^{0}=325.5 \mathrm{lbf} / \mathrm{in}$.).

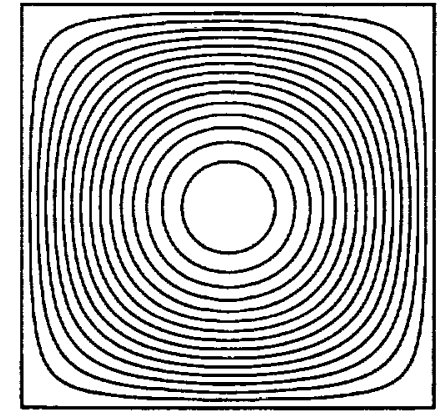

a) $\mathrm{N}_{\mathrm{y}} / \mathrm{N}_{\mathrm{x}}=0,0.5,1$

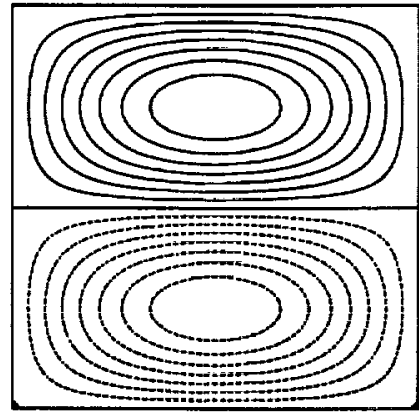

b) $\mathrm{N}_{\mathrm{y}} \mathrm{N}_{\mathrm{x}}=-1,-0.5$

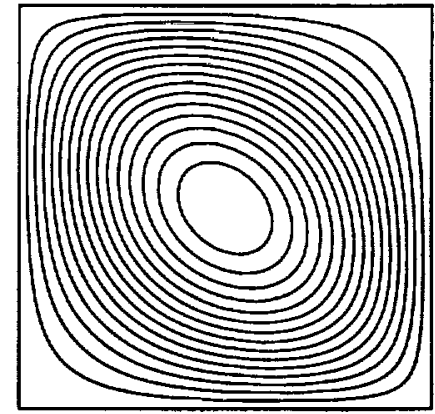

c) $\mathrm{N}_{\mathrm{xy}} / \mathrm{N}_{\mathrm{x}}=1$

Fig. 4 Typical bifurcation mode shapes for square aluminum flat plates subjected to combined axial compression and transverse tension or in-plane shear loads. 


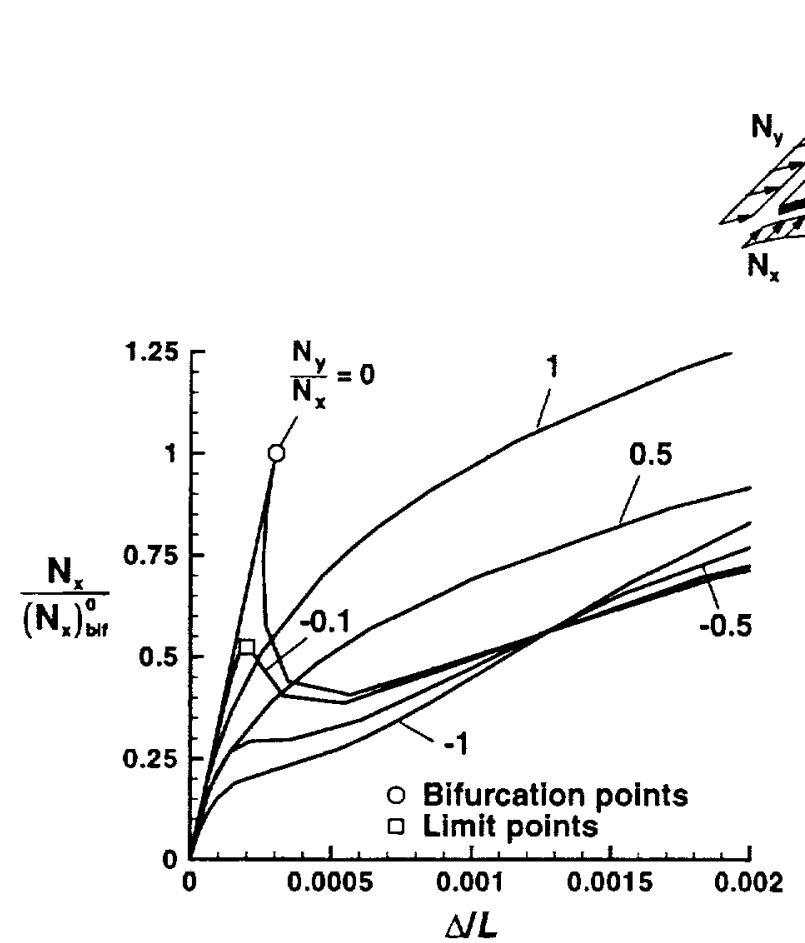

a) Load-end-shortening response

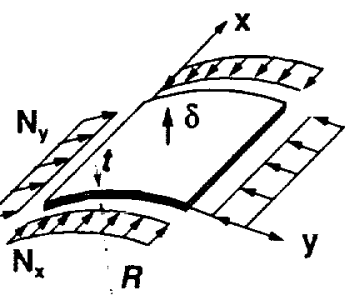

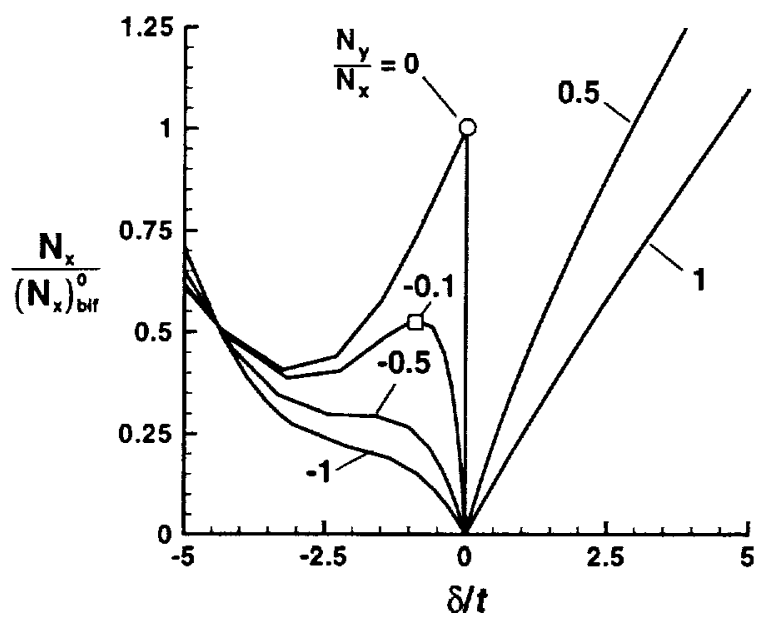

b) Load-normal-displacement response

Fig. 5 Nonlinear response of square aluminum curved panel subjected to combined axial compression and transverse tension or compression loads ( $L=14.0 \mathrm{in}$, $R=60$ in., $t=0.12 \mathrm{in}$., $\left(\mathrm{N}_{\mathrm{x}}\right)^{0}{ }_{\mathrm{bif}}=723.4 \mathrm{lbf} / \mathrm{in}$.).

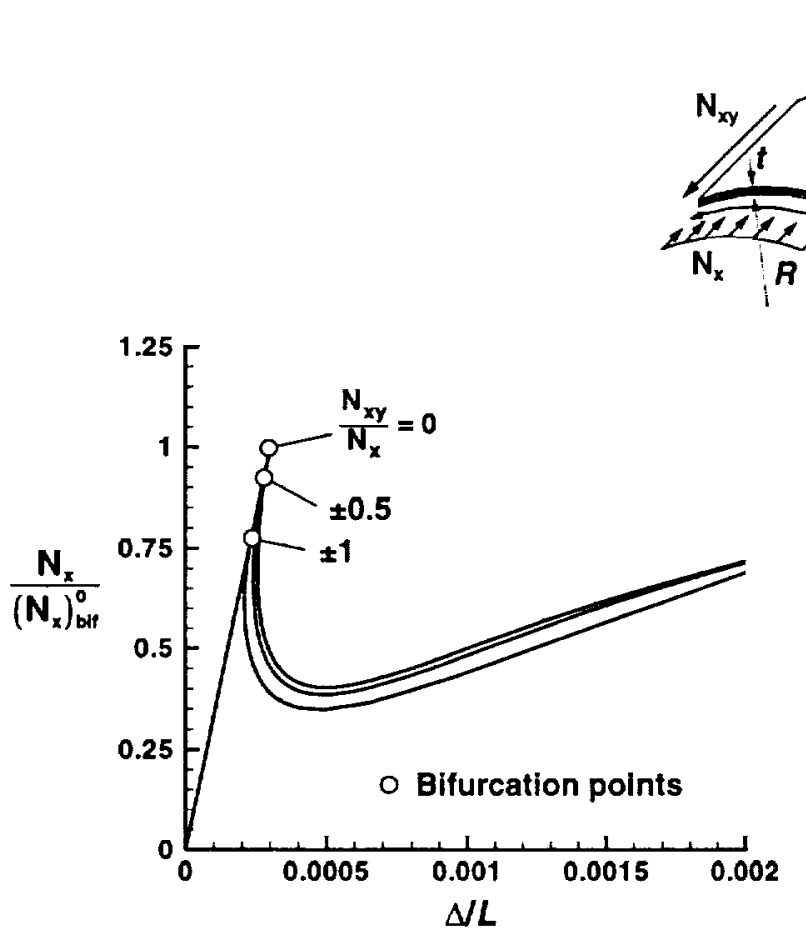

a) Load-end-shortening response

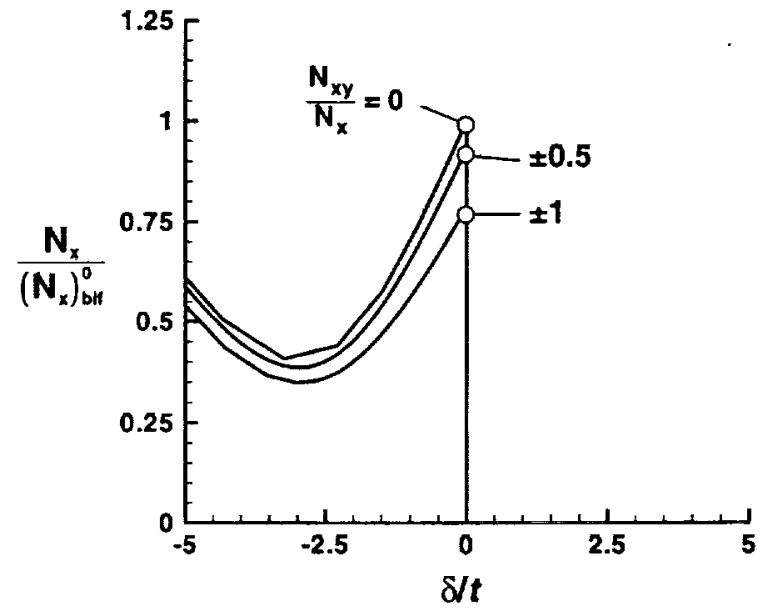

b) Load-normal-displacement response

Fig. 6 Nonlinear response of square aluminum curved panel subjected to combined axial compression and in-plane shear loads $\left(L=14.0 \mathrm{in}\right.$., $R=60 \mathrm{in} ., t=0.12 \mathrm{in}$., $\left(\mathrm{N}_{\mathbf{x}}\right)^{0}{ }_{\mathrm{bif}}=723.4 \mathrm{lb} f / \mathrm{in}$.). 


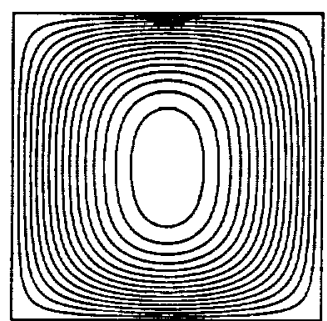

bifurcation mode shape

a) Uniaxial compression, $N_{y} N_{x}=0$

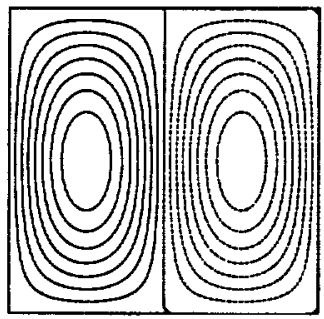

bifurcation mode shape

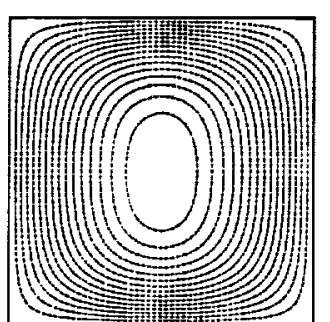

buckling deformation pattern

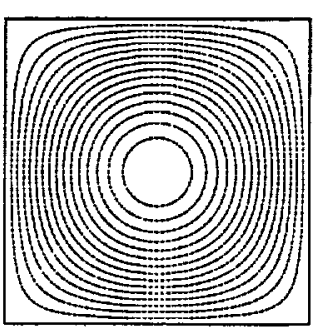

buckling deformation pattern

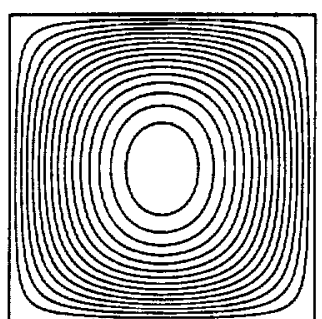

bifurcation mode shape

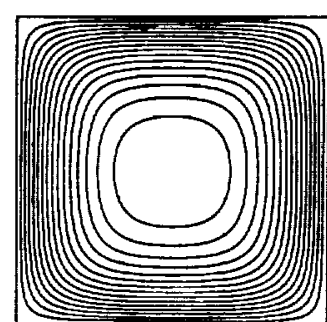

buckling deformation pattem

b) Biaxial compression, $\mathrm{N}_{\mathrm{y}} / \mathrm{N}_{\mathrm{x}}=1.0$

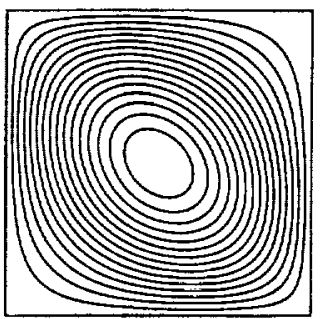

bifurcation mode shape

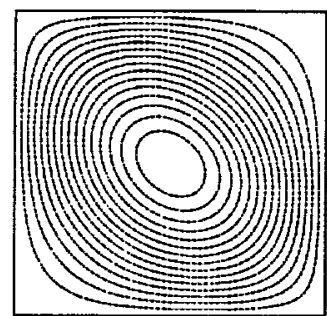

buckling deformation pattern

c) Axial compression and transverse tension, $N_{y} N_{x}=-1$

Fig. 7 Comparison between bifurcation buckling mode shapes and buckling deformation patterns predicted from a nonlinear analysis for curved aluminum panels subjected to combined axial compression and transverse tension or compression loads or combined axial compression and in-plane shear loads.

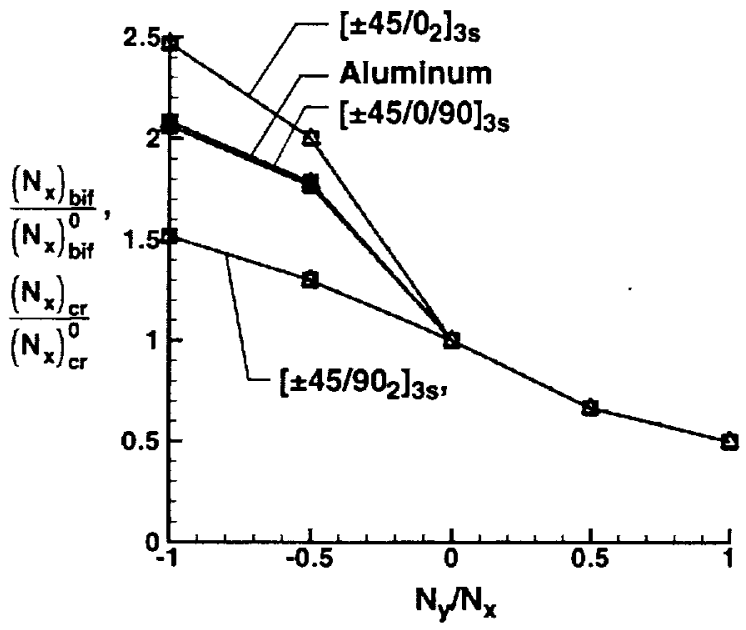

a) $R / t=\infty$
口 Bifurcation buckling load

$\triangle$ Nonlinear buckling load

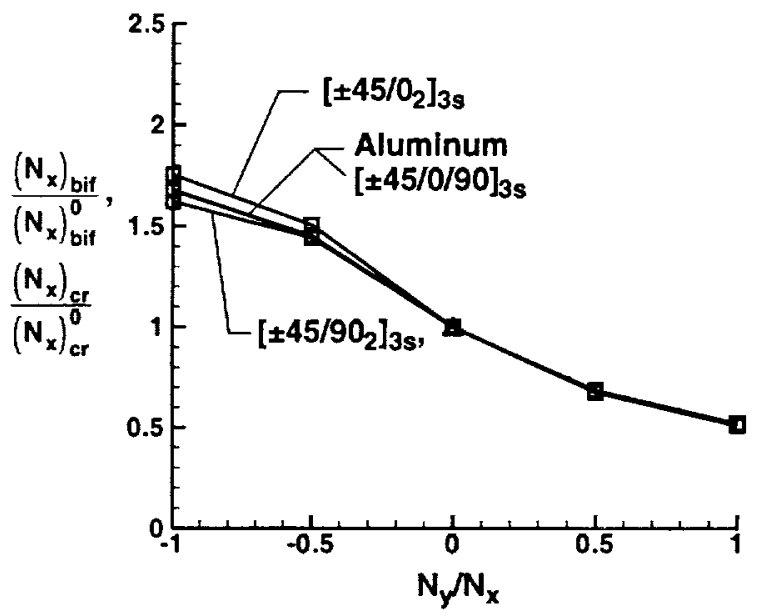

b) $R / t=500$

Fig. 8 Effects of orthotropy and curvature on the nondimensional buckling loads for square panels subjected to combined axial compression and transverse tension or compression loads. 


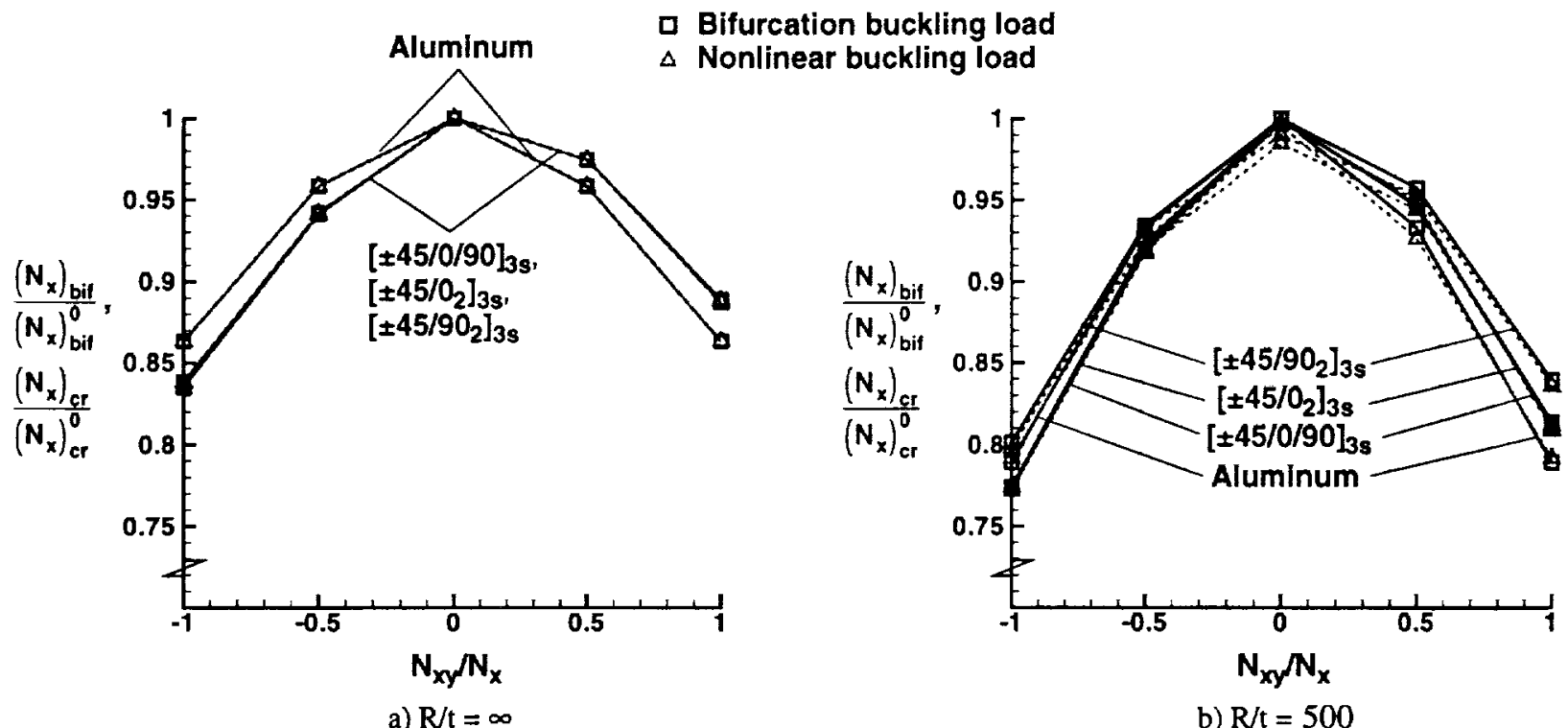

Fig. 9 Effects of orthotropy and curvature on the nondimensional buckling loads for square panels subjected to combined axial compression and in-plane shear loads. 